\title{
DIATHESIS IN SILADANG LANGUAGE
}

\author{
Purwanto Siwi, Susi Ekalestari \\ Faculty of Literature, Universitas Islam Sumatera Utara (UISU) \\ Medan, Indonesia \\ E-mail: purwanto.siwi@yahoo.co.id
}

Received: 2021-06-03

Accepted: 2021-06-19

\begin{abstract}
This paper is to reveal diathesis in Siladang language. Diathesis is a grammatical category that shows the relationship between the participant or subject and the action stated by the verb in the clause. In general, the languages of the world have an active-passive diathesis strategy. This research applies the theory of diathesis proposed by Lyon and adopts descriptive qualitative method in which comparative and inductive treatments are made to the collected data through phenomenological approach. The data (Siladang language) are collected from 2223 informants (native speakers of Siladang language) who live in Sipaga-paga Village and 2006 informants who live in Aek Banir Village. Then, the data are classified based on the language features in universal language empirically. This research shows that Sialdang language has an active-passive diathesis which is one of the important characteristics in an accusative typological language. Apart from having an active-passive diathesis, Siladang language also has a medial diathesis.
\end{abstract}

Keywords: Silandang language, diathesis, typology, active-passive diathesis

\section{Introduction}

Siladang language is a language used by Siladang tribe inhabiting the northern area of Panyabungan, Mandailing Natal Regency, North Sumatra. Geographically, the Siladang community lives in the hilly valley of Tor Sihite, called Sipaga-paga village and AekBanir Village. The special aspect of linguistic discussed in this research is diathesis. In syntactic typology, Siladang language belongs to a language that has SVO pattern in sentence. This canonical SVO pattern reflects the active voice pattern emphasizing the perpetrator or agent more that the patient.

Siladang language is of a syntactically accusative type. Based on the description above, the language of Siladang has an accusative typology which has an active-passive diathesis. Syntax construction with active diathesis contained in the Siladang language is the basic (basic form). Meanwhile, syntactic construction with passive diathesis is a derivative construction (derivative form). The following examples illustrate the constructions with active and passive diathesis of the Siladang language.

(1) Oku mamokol loki-loki i

1SG ACT-hit man DEF

'I hit the man' 


\section{(2) Anjeng idi-sipok bopok \\ Dog DEFPAS-kick father \\ 'The dog was kicked by the father'}

The example of clause (1) describes the syntactic construction of the Siladang language which has active and passive diathesis. As explained above, the difference between activepassive diathesis refers to semantic contradiction so that the two clause examples are categorized as constructions with active diathesis because the subject of the two clauses, namely oku 'I' in clause (1) and bopok'father'in the clause (2) act as an insigator and influence other participants, namely the 'male' loci in clause (1) and the dog i 'the dog' in clause (2).

\section{Literature Review}

According to Lyons (1987: 371-373; Jufrizal 2004: 359) the term diathesis comes from Greek, which means "state", "arrangement", or "function". While the term voice comes from Latin, which means "tone", or "sound". It is used interchangeably or the same in linguistics to refer to the active-passive dichotomy. As has been stated in the introduction to this study that Siladang language belongs to a language that has an active-passive diathesis so it is seen that Siladang language has an SVO canonical sequence pattern that reflects an active sentence pattern emphasizing the actor or agent more than the patient.

Shibatani (1996: 3) states that diathesis (voice) is understood as a mechanism that selects the main syntactic elements, namely the grammatical subject of the basic semantic functions (cases and thematic roles) of the clause. Related to the term diathesis, Kridalaksana (2008: 49) also reveals that diathesis is a grammatical category that shows the relationship between the participant or subject and the actions expressed by the verb in the clause. Shibatani (1996: 3), further, states that in general the languages of the world have a basic diathesis strategy known as active-passive diathesis. The active-passive diathesis conflict refers to the semantic conflict. In active diathesis, the subject acts as an instigator over others or influences others. Conversely, in passive diathesis, the subject is influenced according to the place where the action falls.

Language that has a typology as an accusative language has a passive-active diathesis. Meanwhile, language that has a typology as an ergative language has an ergative and antifan diathesis. Passive diathesis is a diathesis derived from active diathesis. Meanwhile, the anti-passive diathesis is a diathesis derived from ergative diathesis. One example of a language that has an active-passive diathesis is English, which is typologically an accusative language. Meanwhile, Dyirbal language, which is an ergative-typified language, has an ergative diathesis and an anti-fan-derived diathesis.

Regarding passive construction, experts have suggested general features and the process of forming passive constructions are based on passive studies across languages. The characteristics and the process of forming the passive construction can be summarized as follows (Givon, 1990: 566; Foley and Van Valin, Jr. 1994; Dixon, 1994; Palmer, 1994: 16) The process of transitive clauses to form intransitive clauses:

a. The object rises or promotes to occupy the subject position.

b. Subjects are passed to oblique arguments or they can be omitted or optional.

c. Changes occur at the morphological level of verbs to indicate the process of passive construction.

d. Syntactically, passive construction is the process of creating a subject.

e. Passive is a recycling process (cyclic). 
f. Passive is a bound form (in one) clause.

g. Passive is a form of structural transformation that is derivative.

h. Passive set rules (grammar)

English, as an accusative language, clearly recognizes the active-passive dichotomy. In passive diathetic sentences in this language, the patient, theme, receiver (recepient), source or location can function as the subject. Meanwhile, the agent, experience (experiencer), receiver, or source can function as an object of preposition (see Van Valin, Jr. and La Polla, 1999: 140-141).

\section{Research Method}

Descriptive qualitative is adopted in this research in collecting and analyzing the data. The data are taken from Siladang language (meaningful verbal language uttered naturally, accepted, and understood by the native speakers) obtained from 4229 native informants of Siladang language speakers. The informants are from two villages; Sipaga-paga and Aek Banir villages. Therefore, the instruments used in this research is interview. The data are then analyzed by comparing and inducing the language features by using phenomenological approach empirically. As said by Van Valin and La Polla (1999. 2002:3) the linguistic research is aimed at describing the language phenomena related to individual language or universal language.

\section{Results and Discussion}

\subsection{Passive Diathesis in Siladang Language}

Siladang language is a language that has a syntactic accusative typology, so that the Siladang language recognizes active-passive diathesis. An active diathesis sentence is a basic sentence with a passive diathesis in a derivative sentence. According to Chung in Li in Travis (2007), Indonesian according to some experts is considered to have two types of passive, namely passive canonical, for example "Books are read by Ali" and passive which has a surface shape as an object for example "Ali I hit ". Meanwhile, according to Kridalaksana (2008: 49), passive voice is a diathesis which shows that the subject is the goal of the action; for example 'he was hit'. These two types of construction are also found in the Siladang language. In order to facilitate assessment, this part describes and discusses constructions that can be aligned with the passive Indonesian canonical. Canonical passive is original passive or true passive.

The active diathesis in the Siladang language is marked morphologically by the prefix ma- and its allomorphs. The following are examples of sentences with passive diathesis:

(1.1a) Salim man-jual lasino

Salim ACT-sell chilies

'Salim sells chilies'

(1.1b) Lasino di-jual len Salim

Cabai PAS-sell Prep Salim

'Chili sold by Salim'

(1.1c) Lasino ta-jual len Salim

ChiliPAS-sell Prep Salim 


\author{
'Chili sold by Salim' \\ (1.2a) Oding ma-moksh karoteh \\ Brother ACT-burnpaper \\ 'Brother burns paper' \\ (1.2b) Karotehdi-boksh len oding \\ PaperPAS-burn Prep sister \\ 'The paper burned by my sister' \\ (1.3a) Kami ma-nyuan kanas \\ 1PL ACT-plantpineapples \\ 'We planted pineapples' \\ (1.3b) Kanas di-nyuan len kami \\ Pineapples PAS-plant Prep 1PL \\ 'Pineapples are planted by us'
}

As explained previously, Salim's pre-verbal FN 'name of person' in clause (1.1a), oding 'younger' in clause (1.2a), and kami 'we' in clause (1.3a) are grammatical and the same time subject agent. Meanwhile, FN pos-verbal lasino 'chili' in clause (1.1a), karoteh 'paper' in clause (1.2a), and kanas 'pineapple' in clause (1.3a) are both object and patient. The three sentences (1.1a), (1.2a), and (1.3a) are transitive sentences with active diathesis. Semantically, the subject (agent) takes action (action) on the grammatical object. Through the passive construction principle, sentences (1.1a), (1.2a), and (1.3a) can be derived (derived) into passive diathesis sentences as in sentences (1.1b), (1.2b), and (1.3b).

The three sentences (1.1b), (1.2b), and (1.3b) above are derivative sentences (passive sentences) of basic sentences (1.1b), (1.2b), and (1.3b). The process and mechanism of passive construction rules and principles generally occur across languages to accusative languages. In sentences (1.1a) lasino 'chili', (1.2a) karoteh 'paper', and (1.3a) kanas 'pineapple' are objects, while in sentences (1.1b), (1.2b), and (1.3b) lasino 'chili', karoteh 'paper', and kanas 'pineapple' are changed to grammatical subjects. The original subject (in the active voice) Salim 'name of person' in clause (1.1a), oding 'sister' in clause (1.2a), and kami 'we' in clause (1.3a) changes to the oblique relation marked by the preposition len 'by' in sentences (1.1b), (1.2b), and (1.3b) above. Another change in the passive construction is the verb morphology marker. Active markers are replaced by two passive prefixes in Siladang language, namely di- and ta-on sentences (1.1c). Thus, there are two passive prefixes in Siladang language, namely di- and ta-.

The following are the explanation of the behavioral characteristics of passive in Siladang language constructions with respect to each prefix; di- and ta-.

\title{
General Passive with Prefixe di-
}

The passive prefix in the language of Siladang can be attached to all active transitive verbs and can be said to be a passive constituent through subject-demoting passive. Passive with the prefix di- is a general and productive passive in the Siladang language. This passive construction with di- has passive universal characteristics, including: (i) the original clause subject changes its function to become oblique, (ii) the argument of the subject of the nonpassive sentence loses a lot of the characteristics of the pivot behavior, most of which are in passive construction which is not owned by the original object; (iii) the original object in the 
active construction is the only argument of the derivative intransitive verb (passive construction).

Semantically, passive construction with prefix implies that the level of intention or volition of the perpetrator is high. Although the agent (actor) which in the derivative construction (passive sentence) is marked by the preposition len'by' may be omitted, its presence in everyday language tends to be preserved, especially if the perpetrator is animate or implied as an act of intent. The following are examples of common passives with the traits outlined above.

(1.4) Si Badu di-pokol len si Hasan

Si Badu PAS-beat Prep si Hasan

'Badu was beaten by Hasan'

(1.5) Podi a di-gotil len polodong $i$

Rice has PAS-harvest Prep farmer DEF

'The rice has been harvested by the farmer'

(1.6) Hejok di-puyu len kami

RopePAS-spun Prep 1PL

'The rope is spun by us'

Passive constructs (1.4), (1.5), and (1.6) are semantically-pragmatically unusual because of the presence of the phrase lensi hasan 'by si Hasan' (1.4), lenpolodong i 'by the farmer' (1.5), and len kami ' by us' (1.6) are oblique related actors. Passive speech (1.4), (1.5), and (1.6) are more common without the noun actor present. Thus, the actor with an oblique relationship in passive sentences (FN with the preposition len 'by' in Siladang language) does not need to be present. The presence of actors like this is common in the second type of passive construction (topicalisation) such as this sentence: Hejok kami puyu 'Our rope spun'.

\section{Accidental Passive Construction with prefix ta-}

The passive prefix $t a$ - can generally be attached to a transitive verb to form a passive sentence. Different from di- prefixes, passive sentences that appear through prefixes with $t a$ - have the characteristic meaning of 'coincidence' or 'accidental'. Therefore, basically the prefix can be added to transitive verbs which require a general or natural actor. Passive speech with prefixta-, basically, does not use the intermediary (animate actor). However, transitive verbs that desire an animator can also be prefixed with ta- to form passive with the meaning 'accidental' or 'chance'. Thus, passive construction with ta- in the Siladang language has a very low level of willingness and volition from the perpetrator.

If the actor is an animate being (an actor with will), then the actor tends to be preserved although it may also be removed in the passive voice with oblique relation to the marker of the preposition len 'by',. The following are examples of passive sentences with the prefix taderived from basic active sentences (1.1a), (1.2a), and (1.3a)
(1.7) Lasino ta-jual len Salim
Chili PAS-sell Prep Salim
'Chili was sold by Salim'

(1.8) Karoteh ta-boksh len oding

PaperPAS-burn Prep sister

'Paper was burned by sister' 
(1.9) Kanas ta-makan len Jihan

Pineapples PAS-eatPrep Jihan

'Jihan was eaten pineapples'

In the sentences (1.7) - (1.9), the subject which is the only argument for the derivative intransitive verb (prefix ta-) is affected by the action the verb describes. Meanwhile, the role of the actor Salim in sentence (1.7), oding 'younger brother' in sentence (1.8), and 'Jihan' in sentence (1.9) perform an action that is very low. The perversion of prepositional $\mathrm{FN}$ is also possible to hide the role of the perpetrator and to emphasize the meaning of 'coincidence' or accident '.

If the doer is a lifeless or natural being, then the presence of the actor marked by the preposition len 'by' tends to be neglected even though to assert it, may also be maintained. The following are examples of passivity where the culprit is a common or natural noun.

(1.10a) Botu godong ma-nimpo umoh i

StonebigACT-hithouse DEF

'Big stone hit the house '

$$
\begin{aligned}
& \text { (1.10b) Umoh i ta-timpo (len botu godong) } \\
& \text { House DEF PAS-timpa (Prep big rock) } \\
& \text { 'The house was crushed (by a big rock)' }
\end{aligned}
$$

\section{(1.11a) Opi mam-boksh lodong tabu}

Fire ACT-burn plantationsugarcane

'The fire burns sugar cane plantationsugar cane '

\section{(1.11b) Lodong tabu ta-boksh (len opi)}

Sugarcane plantation PAS-burn (Prep api)

'Sugarcane plantation burned (by fire) '

The prefix ta- in the Siladang language also carries the meaning of the aspect of 'able' or 'can' along with passive diathesis. The point is that in addition to carrying a passive diathesis, the prefix with ta-also carries the meaning of the aspect of 'able' or 'can'. If the meaning of the aspect of 'able' or 'can' is included to understand a sentence with a verb prefix ta- then the level of willingness or intention of the doer becomes high as well as the inclusion of di-. In this case, the perpetrator is usually an animate creature or a general noun that is considered to have a will. The doer which is marked by the preposition len 'by' is oblique to this type of construction and tends to be maintained, which indicates the intention of the actor. The following are examples that demonstrate this symptom.

(1.12a) Anggi mambaca buku oku

Younger brother ACT-read book POS1SG

'Younger brother read my book '

(1.12b) Buku oku ta-baca len anggi

Book POS1SG PAS-ASP-readPrep sister

'May book can be read by my sister' 
(1.13a) Aa tajun ma-mocsh botu godong

waterfall ACT-breakbig rock

'The waterfall breaks a big rock'

(1.13b) Botu godong ta-pocah len az tajun

Big rocksPAS-ASP-broken Prep waterfalls

'Big rocks can be broken by waterfalls'

\subsection{Medial Diathesis of Siladang Language}

Besides active-passive diathesis between the two diathesis of accusative language, Siladang also has medial diathesis. Related to the medial diathesis, Shibatani (1996: 17) states that, traditionally, the diathesis is a link between (reference) the subject and the action expressed by the verb. Diathesis is a name for verbal construction according to how the construction expresses an action or state with respect to the subject (active diathesis); subject to action (passive diathesis), is influenced by its own actions (medial / reflexive diathesis). In relation to the three basic oppositions of these categories, Shibatani (1996) suggests three forms (constructions) of verbal levels:

(i) Active form: the subject as an agent, performs an action that extends to a free entity, namely the patient, influencing the patient so that the patient arrives at a certain state.

(ii) Passive form: the subject, the patient is in a certain state as a result of experiencing a change in state caused by the action taken by the agent.

(iii) Medial form: the subject performs actions that affect himself so that the subject experiences changes in circumstances.

Related to the medial diathesis, Shibatani (ed) (1996: 31-33) suggests five grammatical features of medial diathesis:

(i) The medial diathesis verb denotes a reflexive or reciprocal meaning or activity.

(ii) The medial diathesis serves to show the status of beneficiary experienced by the subject for the action. The medial diathesis shows the dual status of the subject, as a source of action and as an entity affected by the action or the place where the influence / action falls.

(iii) The disclosure of actions experienced by the object is understood as actions that are within the subject's circle; the object behaves or belongs to the subject itself.

(iv) The medial diathesis reveals the character of the subject.The resulting consequences are on the subject itself.

(v) The effect of the action taken by the agent / subject; for good or bad goes straight to the subject.

To observe the grammatical behavior associated with the medial diathesis of the Siladang language, the following are the examples of a verbal construction with a medial diathesis with the dual status of the subject, both function as a source of action and simultaneously as an entity that benefits from the action taken. Data presentation and discussion is based on the theory and characteristics of diathesis proposed by Shibatani 
(1996). In the following, the verbal constructions with medial diathesis in the Siladang language show the dual status of the subject; as a source of action and as a form influenced.

(2.1a) Bahar ma-nyapsap boju

Bahar ACT-wash clothes

'Bahar washes clothes'

(2.1b) Bahar ma-nyapsap mukona

Bahar ACT-washface-POS3SG

'Bahar washes his face'

Sentence (2.1a) shows a verbal construction where the verb is marked by the prefix maand is an active diathesis marker, while sentence (2.1b) marks verbs with medial diathesis, the subject (agent) performs activities that affect or influence himself. Furthermore, verbal construction with medial diathesis in Siladang can be indicated by the construction of verb of the prefix ma-. This construction is a reflexive construction.

(2.2a) Jalma i ma-monoh tupai

Guy DEF ACT-kill mouse

'The guy killed the mouse '

(2.2b) Jalma i ma-monoh dagengna (sandiri)

Person DEF ACT-kill himself

'That person kills himself'

The prefix $m a$ - in sentence (2.2a) is the active diathesis, while sentence $(2.2 b)$ marks the verb which has medial diathesis.

The following are verbal constructions where the verb is marked by the prefix ma-. In sentence (2.3), the prefix occurs in the word matinju 'boxing' which is a morphological marker of active diathesis verbal construction. While the prefix $m a$ - in sentences (2.4) and (2.5), namely is the word ma-bakbak 'muttering' in sentence (2.4) and the word ma-weigh 'exchanging ideas' in sentence (2.5) are markers for verbal construction with medial diathesis in the Siladang language which show the meaning of reciprocity (mutually reciprocal).

(2.3) Sisibudok i ma-tinju da jalan

Kids DEF ACT-boxing Prep street

'The kids are boxing each other on the street '

(2.4) Ivong i ma-bakbakjuo

3PL DEF MED-kill also

'They also scold each other'

(2.5) Kudianna sisibudok i pa ma-timbang

Finallychildren DEF PART MED-exchanged ideas

'Finally the children exchanged ideas'

The following different examples are medial diathesis verbal constructions where the verb has zero markings with affix ba-

(2.6a) Angkang ma-mondi-an anggi 
BrotherACT-bath-APL sister

'Brother bathes sister'

(2.6b) Angkang mondi

BrotherMED-takes a bath

'Brother takes a bath'

(2.7a) Uvong kampung mandamaikan kami

Villager ACT-reconcile-BEN 1PL

'Villager reconcile us'

(2.7b) Kami ba-damai

1PLMED-peace

'We are at peace '

The examples in sentences (2.6a) and (2.7a) above show that verbal constructions whose verbs are marked by the confix $m a-\ldots$ - in the sentence and are morphological markers of active diathesis verbal constructions. Meanwhile, sentence (2.6b) shows a medial diathesis verbal construction where the verb has zero mark, namely mondi 'shower' and sentence (2.7b) shows a medial diathesis verbal construction where the verb is marked with the prefix ba-namely badamai 'to make peace'.

The explanation above shows that the medial deathesis in the Siladang language can be marked morphologically by the prefix $\mathrm{ma-}$-, prefix zero, and prefix $b a-$. In addition, the confix ma-...- an also carries the meaning of reciprocity in the Siladang language. The following examples include verbal constructions with medial diathesis.

(2.8) Sisibudok i masi-vamban-an botu

Children DEF MED-throw stone

'The children are throwing stones'

(2.9) Kadua bujing i masi-goyak-an

Two girlsDEF MED-scold

'The two girls scold each other '

(2.10) Kami ta masi-bonci-an

We NEGMED-hate

'We don't hate each other'

The analysis of the medial diathesis shows that Siladang language has grammatical behavior which can be categorized as a language that has a medial diathesis. The prefix main the Siladang language has a role as a verb marker that can mark active and medial diathesis. Meanwhile the prefix $b a$ - in the Siladang language has a role as a verb marker that can mark the active diathesis and the $m a-. .$. - confix in the Siladang language has a role as a verb marker that can mark the medial diathesis. In this regard, the grammatical function has various semantic roles. The determination of the semantic roles related to the diathesis of the Siladang language in relation to the prefix depends on the semantic content of the verb which is marked and the pragmatic functions of the sentence concerned. 


\subsection{Construction with Verba Zero: Topicalisation}

Previously, it is explained that there are a number of Siladang language verbs that can manifest as basic verbs (without affixes) in basic sentence construction. The number of transitive verbs that can stand without affixes ( $m a$ - prefix) in basic sentences is rare. If such a verb is put in the prefix, it is still acceptable. Transitive sentences which are referred to as basic sentences are sentences that have a construction verb with a ma-prefix, which is an active marker prefix. Construction with the zero verb in this section does not mean constructing the basic sentence without the affix. Rather; it is a derivative construction whose verb appears without an affix marker, the verb can appear or stand as a root verb.

The following examples are sentences called the zero construction:

(3.1a) Kami ma-miong botu godong

1PLACT-liftbig rock

'We lift the big rock'

\section{(3.1b) Botugodong kami piong \\ Big rock1JM lift \\ 'The big rock, we lift '}

\section{(3.2a) lana ma-koli tapian}

3SG ACT-dug well

'He dug a well '

\section{(3.2b) Tapian iana koli}

Well3SG dug

'The well, he dug '

If constructions like (3.1) and (3.2) cannot be called basic sentence constructs, of course such constructions are derived constructions. As a derivative construction, it is the zero construction with a passive construction or pentopic construction. To answer this question, a study is needed by presenting examples of the Siladang language and their comparison with the passive constructions of other languages. In this regard, it is necessary to revisit what Chung in Sabathani (1976: 58-92) states regarding the two types of passive in Indonesian. This review is important considering that the Zero construction in Siladang is very similar to the equivalent construction in Indonesian sentences.

There is a strong belief that Indonesian language has two types of passivity, namely passive canonical and passive, whose birth form is in the form of object pentopic.

(3.3) The book was read by Ali 'Buku itu di-baca oleh Ali'.

(3.4) Ali was hit by that person. 'Ali di-pukul oleh orang itu'.

The two examples above are basic passive sentences, called canonical passive. The verb in the sentence is marked by the prefix di- (passive prefix). The following examples are also understood as a type of passive in Indonesian.

(3.5) The book, I read

(3.6) Ali, I hit ‘

Constructions such as (3.5) and (3.6) have a surface form as a topical object. The examining and testing of the grammatical behavior of constructions (3.5) and (3.6) and other forms of choice on the basis of such constructions, show that these constructions are 
difficult to handle with passive theories of accusative languages. Constructions such as (3.5) and (3.6) do not have typological passive characteristics. This fact causes the term 'object precedence' to refer to constructs such as (3.5) and (3.6) which are referred to as zero constructs.

In Indonesian the canonical passive has all the characteristics of the unique passive rule. On the other hand, the object-leading construction does not involve any particular passive morphemic, and the underlying subject does not appear to be transferred to an oblique related element. Presenting objects means pentopic; semantically active, and usually recognized by native speakers as a construction equivalent to the active voice or object pentopic.

(3.7a) Kami man-jual basi tuha
1PLACT-sellscrap metal
'We sell scrap metal '

(3.7b) Basi tuha ta-jual len kami

Scrap metal PAS-jual Prep 1PL

'Scrap metal is sold by us'

(3.7c) Basi tuha kamijual
Scrap metal -TOP 1PLsell
'Scrap metal, we sold'

(3.8a) Oding mamuong osoh

Adik ACT-take outtrash

'Younger brother is taking out the trash '

(3.8b) Osoh di-buong len oding

Garbage PAS-throwPrep sister

'Garbage was thrown away by sister'

(3.8c) Osoh oding buong

Garbage-TOP sisterthrow

'Garbage, Sister threw'

The sentences above show that sentences (3.7a) and (3.8a) are active diathetic sentences and sentences (3.7b) and (3.8b) are passive diathetic sentences. The sentence constructions (3.7c) and (3.8c) are equivalent to the sentence construction in Indonesian called 'object prioritization' or 'topicalization'. If we refer to the theoretical basis and typological passive characteristics and cross-language constructions of zero verbs such as (3.7c) and (3.8c), it is less accurate to call it passive constructions. The construction with the zero verb which is a derivative (sentence) construction in the Siladang language is more appropriate to say as 'pentopic' rather than a passive construction. The designation of this construction as topicalization deals with pragmatic functions in Siladang language sentences.

Furthermore, if we re-examine the sentences (3.7c) and (3.8c) which are the basis for the explanation of why the zero construction is called pentopic not passive. In (3.7c) the subject of the basic construction kami 'we' does not really change the oblique relation of the derivative (passive) construction. Likewise trite tuha 'scrap metal' does not really function as 
a grammatical subject to the derivative clause. In the case of such behavior it is very important to reactivate. For the verb construction, the verb in (3.7c) appears in the basic form (without affixes), in the case of verb construction in complicated passive constructions; marked morphologically by passive prefixes. Semantically, the derivative construction, such as in the example sentence (3.7c), still shows the characteristics of active diathesis, with the evidence that the basic subject kami 'kami' still implies taking action and not being recognized and influenced by the action as described by the verb. The reasons regarding the pragmatic functions which support such a construction can also be called pentopic.

\section{Conclusion}

Based on the study of linguistic typology on linguistic data found in Siladang language, it is found that this language is a syntactically accusative language. The Siladang language recognizes active-passive diathesis. Syntactic constructions with active diathesis are basic constructions, while passive diathesis constructions are derivative constructions. Siladang language recognizes the existence of sentences with passive diathesis, but the discussion of passive construction cannot be based on the theory of linguistic typology so that the nature of behavior and types of passivity in this language have not been broken down in detail. This research tries to reveal and examine the types and traits of passivity in typological Siladang.

The conclusion of this study shows that Siladang language has an active-passive diathesis which is one of the important characteristics in an accusative typological language. Besides having an active-passive diathesis, Siladang language also has a medial diathesis. It is proved by the grammatical behavior of Siladang language which, syntactically, has a grammatical alliance system that treats $A$ the same as $S$ and gives different treatment to $P$. The grammatical alliance system of the Siladang language is described as follows:

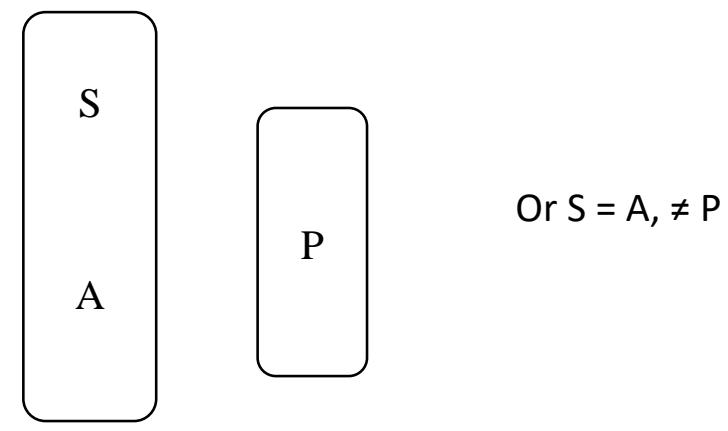

The grammatical alliance system shows that Siladang language treats $A$ the same as $\mathrm{S}$ and differently from $\mathrm{P}$ so that Siladang language can be classified as an accusative typology. Siladang language has an active-passive diathesis which is one of the important features of an accusative typology. Besides active-passive diathesis, Siladang language also has medial diathesis.

\section{References}

Dixon, R.M.W. (2010). Basic Linguistic Theory. Vol 2. Oxford: Oxford University Press. Foley,W.A, Van Valin. Jr.R.D. (1994). Functional Syntax and Universal Grammar. Cambridge: Cambridge Uneversity Press.

Givon. T. (1990). Syntax A Functional-Typological Introduction, Vol II. Amsterdam: John Benjamins Publishing Company. 
Jufrizal. (2004). Struktur Argumen dan Aliansi Gramatikal Bahasa Minangkabau. Denpasar: Program Pascasarjana Universitas Udayana.

Kridalaksana, Harimukti. (2008). Introduction to Word Formation and Word Classes in Indonesia. Depok: Fakultas Sastra Universitas Indonesia Press.

Lyon, John. (1987). Introduction to Theoretical Linguistics. Cambridge: Cambridge University Press.

Palmer, F.R. (1994). Grammatical Roles and Relations.Cambridge: Cambridge University Press.

Shibatani, Masayoshi. (Ed.). (1996). Syntax and Semantic: The Grammar of Causative Construction. New York: Academic Press.

Van Vallin, Jr. Robert D \& Randy J. Lapolla. (2002). Syntax: Structure, Meaning, and Function. Cambridge: Cambridge University Press. 